\section{U.S. DEPARTMENT OF ENERGY}

\section{Office of}

ENERGY EFFICIENCY \& RENEWABLE ENERGY

\title{
Financing Microgrids in the Federal Sector
}

August 2020

FEMP恝: 
(This page intentionally left blank) 


\section{Acknowledgments}

This report was developed for and sponsored by the U.S. Department of Energy's Federal Energy Management Program (FEMP) with Rachel Shepherd as the program manager and lead reviewer. Additional FEMP reviewers include Tracy Niro, Skye Schell, Joanne Lowry, Hayes Jones, Anne Hampson, and Hannah Rabinowitz.

This report was authored by Chuck Kurnik and Phil Voss of the National Renewable Energy Laboratory (NREL). Additional NREL reviewers include Karlynn Cory, Jason Coughlin, Emma Elgqvist, Eliza Hotchkiss, Chandra Shah, Karen Thomas, Deb Vasquez, and Bob Wood. Tom Hattery and Christine Walker with Oak Ridge National Laboratory also reviewed this report. 


\section{List of Acronyms}

$\begin{array}{ll}\text { CHP } & \text { combined heat and power } \\ \text { DER } & \text { distributed energy resource } \\ \text { EaaS } & \text { Energy-as-a-Service } \\ \text { ECM } & \text { energy conservation measure } \\ \text { EPRI } & \text { Electric Power Research Institute } \\ \text { ESA } & \text { energy sales agreement } \\ \text { ESPC } & \text { energy savings performance contract } \\ \text { EUL } & \text { enhanced use lease } \\ \text { FEMP } & \text { Federal Energy Management Program } \\ \text { ITC } & \text { investment tax credit } \\ \text { O\&M } & \text { operations and maintenance } \\ \text { PPA } & \text { power purchase agreement } \\ \text { PV } & \text { photovoltaic } \\ \text { SAIDI } & \text { System Average Interruption Duration Index } \\ \text { SAIFI } & \text { System Average Interruption Frequency Index } \\ \text { TRN } & \text { Technical Resilience Navigator } \\ \text { UESC } & \text { utility energy service contract } \\ \text { UP } & \text { utility privatization } \\ \text { USC } & \text { utility service contract } \\ \end{array}$




\section{Executive Summary}

Recent high-impact events such as hurricanes and wildfires highlight the need for energy system resilience. One potential impact of these events is the loss of utility grid power to federal sites, negatively affecting the ability to carry out their missions. Depending on the need to sustain critical functions, it may be important to continue operations during an outage of the electric grid, or at least have power restored quickly after the event. One approach to addressing this need is through a microgrid. Microgrids can provide a more reliable solution than the traditional approach of using a backup generator at individual buildings.

A microgrid can enhance a site's electrical power system during normal operations, as well as provide reliable backup power to critical loads when electric utility power is interrupted. Many times, certain components of a microgrid (and potentially the entire system) can be justified economically and paid for out of energy savings or avoided costs. In cases where savings can cover the project costs, one of several privately financed procurement mechanisms may be used to implement the project. Procurement options available to all federal agencies include utility energy services contracts (UESC), energy savings performance contracts (ESPC), and utility services contracts (USC); other mechanisms such as a power purchase agreement (PPA), enhanced use lease (EUL), and utility privatization (UP) may also be useful to agencies that have the authority to use them. Implementing a microgrid in a comprehensive effort that also includes energy efficiency can provide an important savings component, while reducing power requirements for critical loads, thus reducing the cost of the microgrid and associated distributed energy resources (DER). However, it can be difficult to achieve enough savings and avoided costs to cover the entire microgrid system, so leveraging these avoided costs in combination with appropriated funds may be necessary to implement the full project.

When a site is deciding if a microgrid is the best solution, activities early in the process include identifying critical loads and existing DERs, conversations with the local electric utility, and implementation options that work best for the agency and site.

This paper explores procurement options and agreements that may be useful to federal agencies interested in implementing microgrids at their sites. Microgrid complexities, implementation considerations, and suggestions to get started are also discussed. This information will be most useful to agencies when they are exploring electric energy system resilience options and/or considering different procurement options to meet their needs. 


\section{Table of Contents}

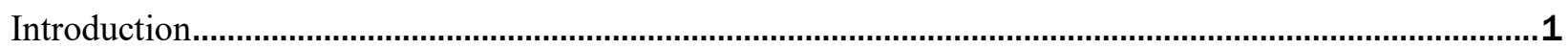

Traditional Approach to Backup Power.............................................................................................

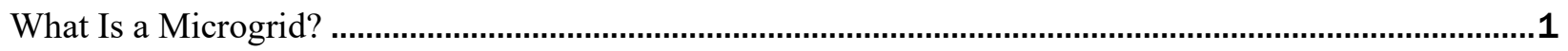

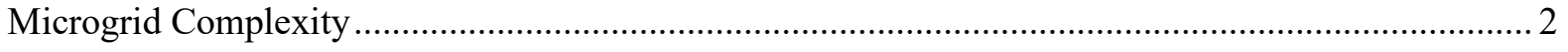

Should My Agency Pursue a Microgrid?

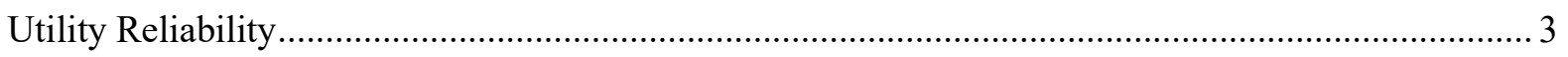

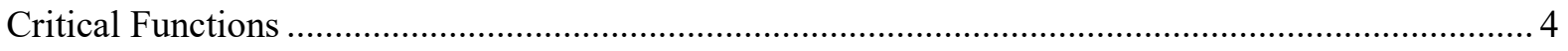

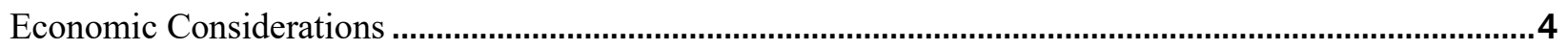

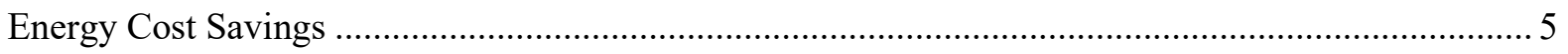

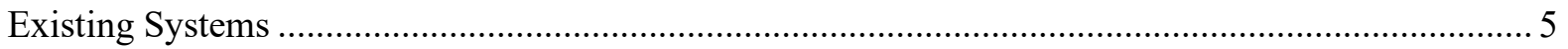

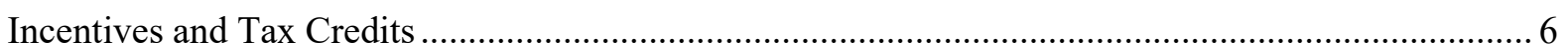

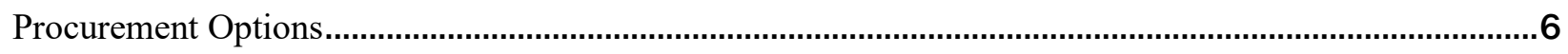

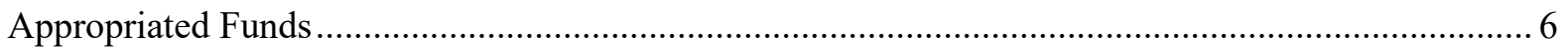

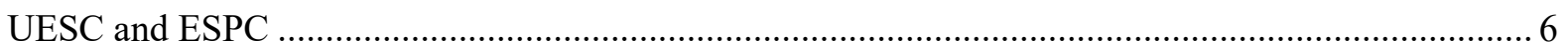

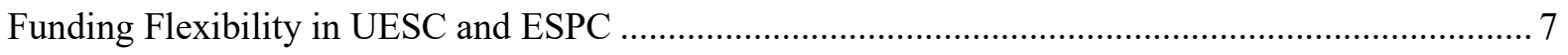

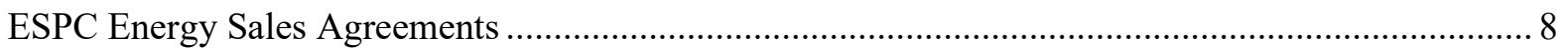

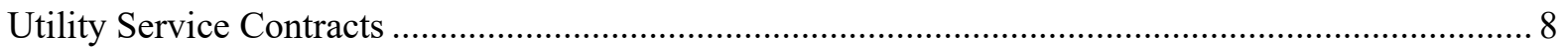

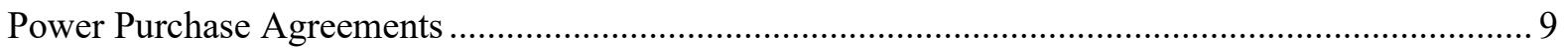

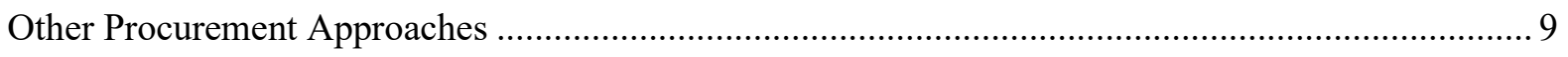

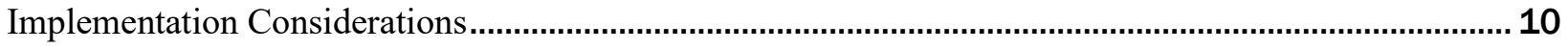

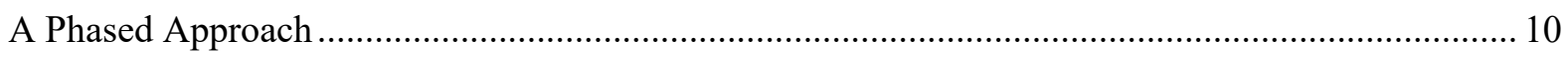

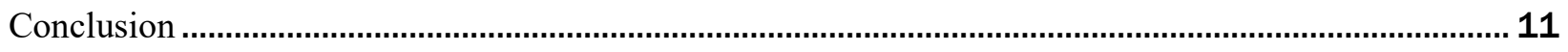

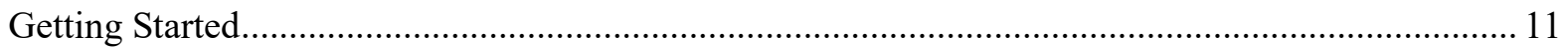

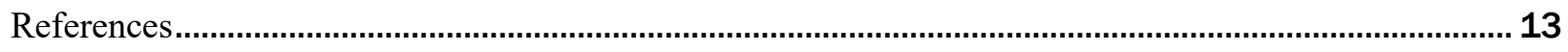

\section{List of Figures}

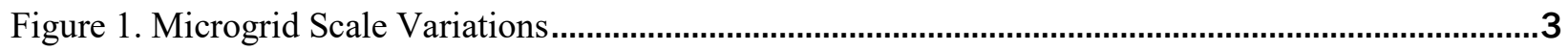




\section{Introduction}

Recent high-impact events such as hurricanes and wildfires highlight the need for energy system resilience. ${ }^{1}$ One potential impact of these events is the loss of utility grid power to federal sites, negatively affecting the ability to carry out their missions. Depending on the need to sustain critical functions, it may be important for a load or multiple loads to operate during an outage of the electric grid, or at least have power restored quickly after the event. One approach to addressing this need is through a microgrid.

A microgrid can enhance a site's electrical power system during normal operations, as well as provide reliable backup power to critical loads when electric utility power is interrupted. When components of a microgrid (and potentially the entire system) can be justified economically and paid for out of energy savings or avoided costs, implementation by one of several privately financed federal procurement mechanisms is possible. However, it is typically difficult to achieve enough savings and avoided costs to cover the design, equipment, and installation of certain microgrid components that are required to integrate the system. This paper explores procurement options and agreements that may be useful to federal agencies interested in implementing microgrids at their sites. This information will be most useful to agencies when they are exploring electric energy system resilience options and/or considering different procurement options to meet their needs.

\section{Traditional Approach to Backup Power}

The most common approach to providing backup electricity at a site is a backup generator directly connected to a single building. In this scenario, each building with critical loads has its own backup generator. If one of the generators should fail during a power outage, the building served will be without power until the generator is repaired or replaced, or until grid power is restored. To ensure reliability when needed during a utility power outage, these generators require monthly scheduled maintenance and access to fuel. Generators are often oversized, causing them to operate inefficiently. Battery energy storage systems are becoming more common; however, cost-effectiveness depends on site-specific factors such as load profile and energy rates, and batteries are not typically sized to provide energy for the same duration as a backup generator.

\section{What Is a Microgrid?}

A microgrid is comprised of distributed energy resources (DERs) interconnected through the site's electrical distribution system and provides power to designated critical loads upon loss of the primary energy source. ${ }^{2}$ Microgrids are typically managed through a central controller that monitors the system operating parameters, coordinates DERs (e.g., renewable energy, energy storage, generators), balances and controls electrical loads, and is responsible for disconnection and reconnection of the microgrid to the primary grid (Booth et al. 2019). A microgrid can serve a single building or can provide power to multiple buildings or loads at a site.

A microgrid is different from an emergency backup generator in several strategic ways. First, a backup generator only operates to provide power when grid power is not available or during periodic testing, while a microgrid can interact with the utility (primary) grid and operate in either grid-connected or island mode ${ }^{3}$. Next, microgrids can integrate on-site renewable energy systems and multiple generators for redundancy across multiple buildings - if one generator fails, priority critical loads can still operate. In addition, according to the International Organization for Standardization (ISO) a typical backup generator (featuring a service

\footnotetext{
${ }^{1}$ According to FEMP "Resilience refers broadly to the ability to anticipate, prepare for, and adapt to changing conditions and to withstand, respond to, and recover rapidly from disruptions." For more information, see Federal Energy Management Program, "An Integrated Approach to Resilience,” accessed May 6, 2020. https://www.energy.gov/sites/prod/files/2019/05/f62/femp-resilience_0.pdf. ${ }^{2}$ The U.S. Department of Energy Microgrid Exchange Group defines a microgrid as follows: "A microgrid is a group of interconnected loads and distributed energy resources within clearly defined electrical boundaries that acts as a single controllable entity with respect to the grid. A microgrid can connect and disconnect from the grid to enable it to operate in both grid-connected or island-mode."

${ }^{3}$ Island mode is when the site disconnects from their electric utility and operates only with its on-site DERs.
} 
rating of "standby" compared to a "continuous" or "prime" power rating) is designed to run no more than 200 total hours per year, including testing and maintenance (International Organization for Standardization 2018). The components and cooling system of a backup generator are not designed to handle the heat generated by extended run times, limiting the time that resilient power can be sustained during an outage. However, a microgrid can be designed to operate continuously during both normal operations and long duration outages.

\section{Microgrid Complexity}

While microgrids provide benefits over traditional backup generators, they are typically more complex and can be expensive to install. Each site is different and requires tailored analysis, engineering, and equipment to implement and operate a microgrid successfully. A microgrid integrates the functions of several components that may or may not already exist at a site, such as on-site generation [e.g., solar photovoltaics (PV), backup generators] and building automation systems (BAS). A microgrid may require modifications to existing on-site generation and additional functionality that may not exist, such as energy storage or remote-controlled electrical switchgear. Proper integration of each component into the system is critical to microgrid functionality.

Control of the microgrid frequently requires communication between components, which may benefit from the installation of a communication network separate from the existing network on site. Whether a new system is installed or the existing system is used, the controls and communication network will be subject to the federal Risk Management Framework, ${ }^{4}$ and any other utility, agency, and facility cybersecurity requirements.

Specialized agreements with the electric utility are another factor that contributes to microgrid complexity. DERs such as PV require an interconnection agreement, and combined heat and power (CHP) may require a "parallel operation" agreement. Since microgrids can disconnect from the utility grid, more complex agreements with the utility may be required. Changes in electricity rate tariffs may result from adding on-site generation and should be considered when assessing economics. For all of these reasons, discussions with the utility company should occur early in the planning process to ensure understanding of all utility requirements, if the microgrid may be beneficial to the utility grid, and if the utility may be willing to participate financially.

Additionally, if agency staff will be operating and maintaining the system, microgrids will require specialized training for staff to perform these functions. The microgrid control system is a computer network and requires technical knowledge, skills, and abilities above and beyond those required for maintaining backup generators.

Finally, microgrids can be deployed at several different scales, from powering a single building to powering an entire campus via a substation, as shown in Figure 1.

\footnotetext{
${ }^{4}$ See National Institute of Standards and Technology, “Risk Management Framework (RMF) Overview,” accessed June 7, 2020.

https://csrc.nist.gov/projects/risk-management/risk-management-framework-(RMF)-Overview.
} 


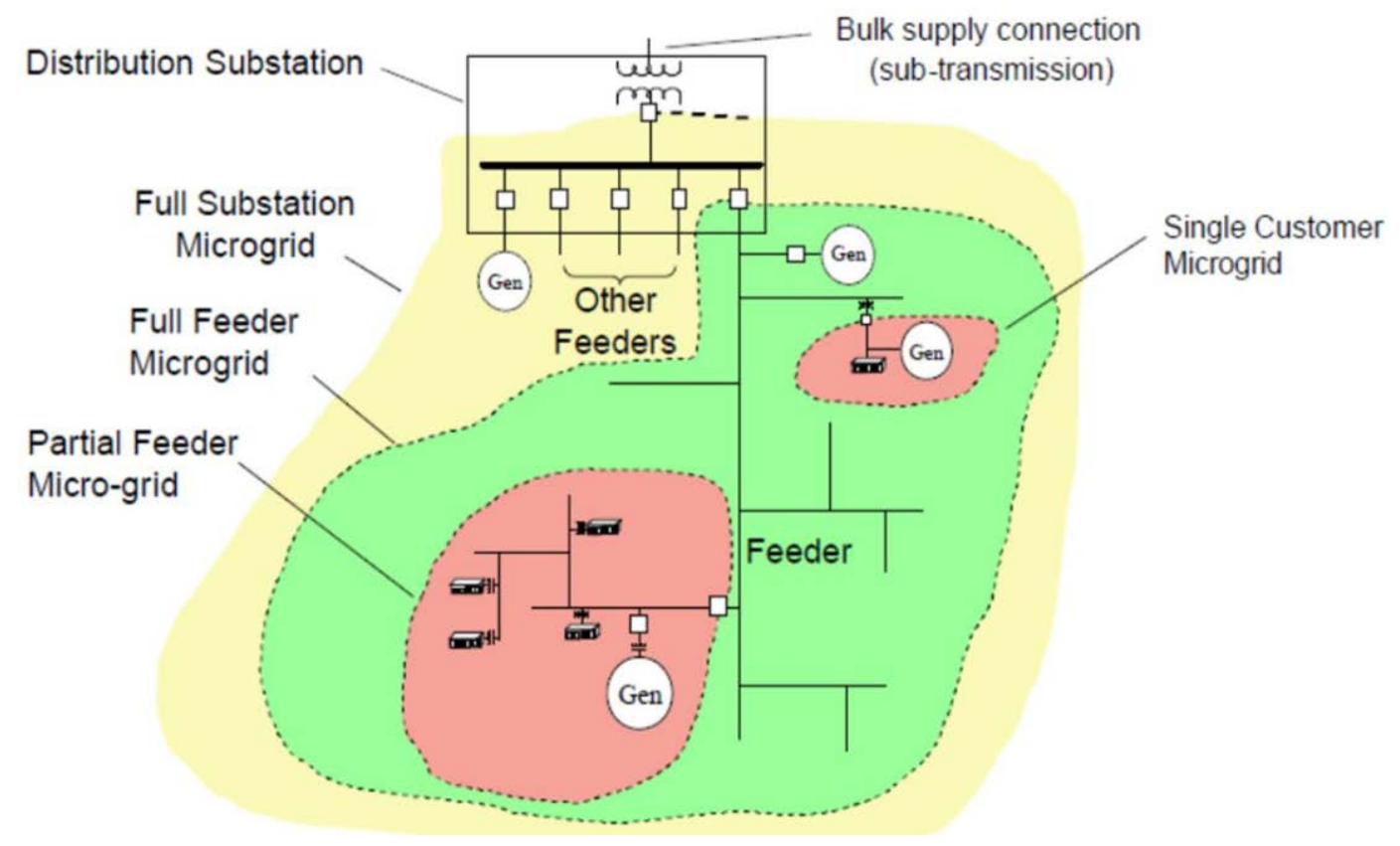

Figure 1. Microgrid Scale Variations

Source: EPRI, 2016

\section{Should My Agency Pursue a Microgrid?}

The need for electrical energy resilience is the main driver in the decision to pursue a microgrid. Agency leadership and stakeholders must identify the risks that could result in an electric power outage and prioritize their critical functions and assets to determine if a microgrid is beneficial at any of its facilities. Hazards may be location dependent (such as hurricane, tornado, or earthquake prone areas), related to power quality or reliability, or based on a facility's life safety or security requirements. For example, a medical campus may be a candidate for a microgrid because an extended outage beyond the capability of backup generators could result in life safety issues, while an administrative building may not have such concerns. As another example, a site may be used as a staging area or emergency shelter for the community during a natural disaster. In this case, operations may need to continue or even increase during a disaster as the site provides needed services such as communications, staging, medical care, and operations management. Utility reliability and critical functions are key considerations in determining the need for a microgrid at a particular site.

\section{Utility Reliability}

If the site's electric utility has a history of reliability issues, it may make sense to install a microgrid to provide more reliable power. For example, a facility may be located at the end of a long transmission or distribution line, making it difficult to ensure needed reliability levels. An agency or the utility may have records of electrical outages, their durations, and the frequencies of such outages at each of its sites. The reliability of an electric utility system is typically measured using two metrics, calculated on an annual basis: outage frequency [System Average Interruption Frequency Index (SAIFI)], and outage duration [System Average Interruption Duration Index (SAIDI)] (IEEE 2012). Reliability information by utility can be found in the U.S. Energy Information Administration "Annual Electric Power Industry Report" (EIA 2019). ${ }^{5}$ Reliability and power

\footnotetext{
${ }^{5}$ See U.S. Energy Information Administration, “Annual Electric Power Industry Report (EIA-861 Data File),” accessed May 6, 2020. https://www.eia.gov/electricity/data/eia861/. Look for the heading titled "Reliability."
} 
infrastructure needs should be discussed with the utility to determine options to address the issues prior to deciding whether a microgrid is the best solution.

In addition to reliability of the electric utility, the agency must also consider the condition of its onsite electrical distribution infrastructure. The site's distribution system is the foundation for a microgrid - if it is old and/or has been poorly maintained, it can be a contributing factor to reduced reliability of the electricity supply. If this is the case, the agency should complete required upgrades before or during microgrid installation.

\section{Critical Functions}

Evaluation of the site's critical loads can help determine the required level of backup generation, whether for a single building or an entire campus. Critical functions are tied back to the agency or site critical mission (or missions), and the functions supporting that mission. Loads that support critical functions are the highest priority for backup energy. Prioritization of those critical loads will also be important for microgrid planning and design. The U.S. Department of Energy Federal Energy Management Program (FEMP) has developed the Technical Resilience Navigator (TRN), a web-based tool to assist federal agencies in identifying vulnerabilities and developing solutions to address their resilience needs (FEMP 2020a). The TRN "Site-Level Planning" and "Baseline Development" modules can help in identifying priorities and documenting critical loads for a particular site.

If operations must continue during a utility grid outage, a microgrid can be designed to offer a more reliable solution than stand-alone backup generators for individual buildings. A microgrid can tie together (i.e., network) multiple generators such that a critical load can be served by many - if a local generator fails, the others can share the critical load.

Continuing to operate only certain loads during a utility grid outage may also be a consideration. There may be a load for a specific set of buildings, a single building, or an area within a building that could affect life safety issues, such as a hospital. Unplanned interruption of some loads could result in a loss of value, such as a continuous laboratory experiment. Some critical loads may even have national security implications in the case of military bases and other highly secure federal facilities.

\section{Economic Considerations}

Microgrids are typically costly, so a site must determine the level of added resilience needed to determine if the expenditure is necessary. When a site loses power, the impact may be monetary losses (such as food or medicine spoilage, lost business, or lost productivity) or non-monetary losses (such as life safety or security issues). Microgrids can help avoid these losses, and the value of these avoided losses is known as the value of resilience. Currently, there is no widely accepted approach to fully monetize the value of resilience-resilience will be valued differently based on agency or site priorities. It is important to note that these avoided losses can be included in a narrative justification for a microgrid but cannot currently be included in the economic calculation as the timing, frequency, or duration of unexpected electrical outages is unknown. Research is underway to explore options for monetizing the value of resilience through government incentives, reduced mortgage rates, or reduced insurance rates, but these are not available to federal agencies at this time. When considering a microgrid project it would be worthwhile to check with DOE FEMP or your agency to see if progress has been made on this potential opportunity.

Some site factors can enhance project economics to make a microgrid more attractive. These include benefits during times of normal site operation rather than only during a power outage. A microgrid and its integrated DERs may provide economic benefits in the form of energy savings, reduced operation and maintenance (O\&M) expenses, and/or avoided costs of replacing aging equipment. Avoided equipment replacement costs may range from obviating the need to upgrade aging on-site electrical distribution, to eliminating replacement 
of backup generators, or even eliminating the need for individual boilers by implementation of a CHP central plant.

Additional factors will vary by state, region, and utility provider and can contribute to the complexity of microgrid implementation. These factors are described below and most of the information is derived from the Electric Power Research Institute (EPRI 2016).

\section{Energy Cost Savings}

Some assets included in a microgrid could provide energy cost savings in several ways. First, operating on-site DERs may be less expensive than purchasing electricity from the local utility. For example, a natural gas turbine may provide CHP to a site more cost effectively than purchasing electricity and fuel to produce steam with boilers. In many markets in the United States, on-site PV electricity production is competitive with utility pricing and can reduce the amount of energy purchased from the local utility. Similarly, the utility may have high demand pricing or time-of-use rates. Distributed energy or energy storage assets could be operated to manage peak loads, or at the time when higher time-of-use rates are in effect, to reduce utility costs.

In addition, the microgrid could allow the facility to participate in ancillary services markets such as voltage or frequency regulation or demand response programs. The value that this provides to the utility grid could help offset some of the costs of the microgrid assets. In some instances, it may be possible to sell excess power to the grid at certain peak times, and participation in curtailment during these times may provide significant cost savings.

The amount of savings generated by a microgrid system will impact the ability of a third party to costeffectively finance the installation of all or part of that system. This approach is discussed further in the Procurement Options section.

\section{Existing Systems}

Existing on-site generation and/or energy storage may be leveraged for the planned microgrid and can reduce the need for procuring new generation. DERs like solar PV, backup generators, and CHP can all be used within the microgrid. Likewise, building automation systems can be used to manage building loads, thus reducing power requirements, and enabling the microgrid to operate longer in island mode.

These existing systems can reduce the capital cost of a microgrid system and may define the approach for designing and implementing a microgrid. For example, if a site has a combustion turbine for a CHP system, this can be the backbone of the microgrid. Likewise, if a site has several large diesel backup generators at individual buildings, it may be possible to network them to be operated more efficiently in load-sharing mode, while also providing redundancy. Fossil fuel-powered generators require access to fuel by way of a pipeline (e.g., natural gas) or delivery trucks. The site must consider fuel availability during a utility grid outage or larger community emergency (e.g., road blockages or destruction due to an earthquake or tornado), as well as space needed for on-site fuel storage, to ensure their resilience needs are met.

Grid-tied PV systems are "grid following," so are designed to cease power production when the utility grid goes down. This is because an inverter only produces power when it sees voltage from the grid. With proper controls, combustion turbines and generators can operate as "grid-forming" sources to provide the voltage and frequency needed for the grid following systems to operate. With a grid-forming source, PV generation will resume, and will help extend fuel supplies to allow the microgrid to operate longer in island mode. Integration and control of the PV system might be required to regulate the generator loading. Energy storage in conjunction with PV can further reduce the need to operate fossil-fueled turbines or generators, further extending fuel supplies. 
While DERs that are already installed and in use at the site may be beneficial to include in the microgrid, if a third party currently owns, operates, and maintains the system, the contractual requirements of that arrangement will need to be reviewed to determine if the DER can be utilized in the microgrid.

\section{Incentives and Tax Credits}

In addition to avoided costs, some technologies may qualify for various financial incentives, which can be used to improve the project economics. State and local policies, such as renewable portfolio standards (RPS), may result in valuation of renewable energy certificates (RECs), net metering, and energy storage that may make microgrid assets more economically attractive. For example, both California and Massachusetts offer incentives for battery energy storage projects, and many states and utilities provide incentives for CHP systems. ${ }^{6}$ A detailed, searchable listing of available state and utility policies and incentives can be found at the Database of State Incentives for Renewables \& Efficiency (DSIRE) website (N.C. Clean Energy Technology Center 2020a).

There are also federal tax incentives for various technologies, such as investment tax credits (ITCs) available for solar photovoltaics (FEMP 2019a), battery storage (NREL 2018), CHP (N.C. Clean Energy Technology Center 2020b) and other technologies. The Modified Accelerated Cost Recovery System (MACRS) allows for capital cost recovery through tax deductions, and some jurisdictions may have property or sales tax exemptions for energy efficiency or DERs. While federal agencies cannot take advantage of tax incentives, one approach is to work with a private developer who will own, operate, and maintain the system and can monetize the incentives and pass most or all of the value through to the federal agency to make a microgrid more costeffective. These incentives do change over time, so it is recommended to check the DSIRE website for up-todate information.

\section{Procurement Options}

Securing funding for microgrids can be challenging due to the significant capital costs. Procurement options currently available to implement a microgrid may include traditional appropriations, a utility energy service contract (UESC), an energy savings performance contract (ESPC), or a special facilities agreement with the serving utility. A power purchase agreement (PPA) may be used where allowable, and there are other less common options that are addressed at the end of this section.

\section{Appropriated Funds}

If sufficient government funding (i.e., direct appropriations) is available, all components of the microgrid could be procured and implemented through standard procurement procedures. Once the total and critical electrical loads of the facility are documented, and the microgrid system designed to the extent that the implementation costs are well understood, funding can be requested. However, there are challenges associated with dependence on appropriations as the sole funding source for a microgrid due to funding limitations and competing priorities that define the amount of funding available at any given time. Appropriations are typically requested on an annual basis, making it difficult to plan and budget for a multi-year phased implementation. As noted in Implementation Considerations section below, ideally the government would have funds available to implement the microgrid system as a single procurement.

\section{UESC and ESPC}

If the microgrid as a whole is life-cycle cost effective, it can be implemented using private funding under a federal performance contracting mechanism, such as a Utility Energy Service Contract (UESC) or Energy Savings Performance Contract (ESPC). With a UESC, an agency contracts with an eligible serving utility for energy- and water-efficiency improvements and demand reduction services. An ESPC is a competitively

\footnotetext{
${ }^{6}$ For more information see the EPA CHP Partnership's dCHPP database, accessed May 29, 2020. https://www.epa.gov/chp/dchpp-chppolicies-and-incentives-database.
} 
awarded contract between an agency and an energy service company (ESCO), with streamlined approaches to satisfy the competition requirement. UESCs and ESPCs offer a number of advantages to the government but are most often pursued because an agency lacks the funds to implement a desired energy project with appropriations. With either of these mechanisms, the contractor provides the upfront capital for design and installation and is paid from annual savings generated by the project over a maximum contract term of up to 25 years (FEMP 2020b and FEMP 2020c). ESPC legislation requires savings to exceed payments in each year of the contract (FEMP 2020b). While UESC authority does not have the same annual savings requirement, it is intended that savings exceed payments over the contract term (FEMP 2020c).

As long as the overall project is life-cycle cost effective ${ }^{7}$, the generation assets, systems, and controls that form the microgrid can be financed and implemented under a single procurement. Legislation requires that plans for equipment operations and maintenance $(\mathrm{O} \& \mathrm{M})$, repair and replacement, recommissioning, and $\mathrm{M} \& \mathrm{~V}$ be included for all energy conservation measures (ECMs), and system commissioning must be completed and documented prior to project acceptance. Annual measurement and verification $(\mathrm{M} \& \mathrm{~V})$ of system performance is required by ESPC legislation. Under a UESC, performance assurance can be accomplished through M\&V or as part of the recommissioning services. In both mechanisms, the actual measurements and resulting savings must be documented annually for the full term of the contract.

As previously noted, resilience can be difficult to monetize and microgrids on their own are not typically costeffective. While some components could result in energy and cost savings (such as DERs that provide power during normal operations and reduce utility costs), other components may not (such as switchgear, controllers, and potential additional distribution). Implementing a microgrid as part of a comprehensive project that includes energy efficiency not only reduces annual energy costs, it also decreases the power needed for critical loads which can result in reduced size and cost of the microgrid. In addition, bundling ECMs that have a shorter payback into the project leverages additional energy cost savings to help pay for the microgrid.

Other energy-related cost savings can also be used as payment towards the project cost. For example, if the microgrid or ECMs bundled into the project are upgrades from older, maintenance-intensive equipment such as backup generators or HVAC equipment, the O\&M cost savings can be applied as payments towards a UESC or ESPC project. The agency must be certain the savings are real and can be verified. If the agency has budgeted for replacement of equipment that will be avoided by implementation of the UESC or ESPC, this avoided cost can also be applied to reduce the implementation cost of the project. More information can be found in FEMP's Practical Guide to Savings and Payments in FEMP ESPC Task Orders (FEMP 2009).

The General Services Administration (GSA) implemented a 55-MW microgrid as part of a comprehensive ESPC project at the Food and Drug Administration (FDA) campus in White Oak, MD (EERE 2020a). CHP provides the backbone of the microgrid, which also includes fixed and tracking PV systems, along with efficiency measures, resulting in significant energy and O\&M savings in addition to enhanced resilience. At the time of writing, microgrids are being investigated in several UESC and ESPC projects that are under development.

\section{Funding Flexibility in UESC and ESPC}

Where possible, implementing the microgrid project in a comprehensive and integrated manner is a preferred strategy rather than taking a piecemeal approach based on funding available at a given time. Agencies may combine government appropriations and private funding to accomplish this. ${ }^{8}$ In particular, agencies may choose to use appropriations to cover components integral to the microgrid system that are not cost effective

\footnotetext{
${ }^{7}$ In UESC or ESPC projects, the life-cycle cost (LCC) effectiveness may be calculated on an aggregated, total project basis. A comprehensive project may include ECMs (including a microgrid) whose economics are supported by other ECMs. An individual ECM may or may not be LCC effective, however the project as a whole must be LCC effective.

${ }^{8} 42$ U.S.C. $\S 8253(\mathrm{f})(10)(B)$ specifically authorizes federal agencies to use "any combination" of appropriated funds and private financing.
} 
based solely on energy savings. ${ }^{9}$ This strategic use of appropriations and leveraging of avoided costs can enhance the viability of resilience projects implemented with a performance contracting mechanism. Agencies must determine the source of appropriations to ensure that it is appropriate to combine with financing.

\section{ESPC Energy Sales Agreements}

ESPC Energy Sales Agreements (ESAs) ${ }^{10}$ use the ESPC authority to implement distributed energy projects on federal buildings or land. ESAs are similar to power purchase agreements (PPAs), which are further described below, but are implemented as an ECM within an ESPC. The ESA ECM is initially privately owned to potentially qualify for tax incentives. The federal agency purchases the electricity it produces with guaranteed cost savings in the form of a lower electric rate than currently paid to the electric utility. The ESCO owns, operates, and maintains the ECM, and any tax incentives (e.g., investment tax credits, accelerated depreciation, state/local incentives), RECs, or other incentives can be applied by the ESCO to reduce the ESA ECM price to benefit the agency. An ESA ECM could be a component of a microgrid that is implemented in a comprehensive ESPC project to contribute to resilience needs.

ESPC ESAs provide two major advantages as compared to PPAs, a similar procurement option and described in detail below. First, while civilian agencies are generally limited to a 10-year PPA term, a 20-year maximum term is allowed for ESA ECMs (IRS Revenue Procedure 2017-19). A longer term makes it possible to finance projects that would not be economic in only 10 years. The second advantage is the ability to implement ESA ECMs as part of a comprehensive ESPC project to achieve energy efficiency to reduce costs and leverage savings, while allowing for integration within the larger microgrid project.

\section{Utility Service Contracts}

A Utility Service Contract (USC) is a bilateral agreement between a serving distribution utility and a federal agency. An agency may enter a USC for electric or natural gas service connection, for demand side management services, or for "special facilities services" among other service options. A USC allows for special facilities to be financed, installed, owned, and maintained by the utility on the customer's side of the meter, so development of a microgrid and functionality service may be initiated as a special facilities service if the utility and agency agree. This may be an ideal option when an agency is interested in microgrid functionality as a service, and when energy savings and available appropriations combined are inadequate to cover the microgrid cost. An advantage of a USC is that an agency can pay the utility for the microgrid over time with a "facilities charge," upfront with agency funds, or a combination of the two.

For example, if a site needs to improve energy resilience where a utility is considering electrical distribution infrastructure upgrades to improve power reliability or quality, support additional load, address congestion or other distribution infrastructure issues, a microgrid may provide a mutually beneficial solution. The utility and the customer will discuss technical solutions, associated costs, and benefits to both parties. If a microgrid is more economically attractive and beneficial to the utility grid and surrounding community than upgrading or expanding the utility's infrastructure, it may be possible to share implementation costs. If the microgrid and special facilities service provides enough support to the utility grid and surrounding community, the utility may get approval to socialize the costs across all benefitting customers with minimal or no cost to the ordering agency. An agency should check with their eligible serving utilities to determine what programs or services they may be able to offer.

The Naval Construction Battalion Center in Gulfport, MS is taking a phased approach to implementing a microgrid system through a partnership with their serving utility (EERE 2020b). A 3.5MW PV array was completed in Phase 1, and Phase 2 will include battery storage, backup generation, and a microgrid system that

\footnotetext{
${ }^{9}$ Each agency will need to verify their policy regarding program funds that can be applied to ESPC or UESC projects.

${ }^{10}$ For more information on ESPC ESAs see FEMP, "Energy Savings Performance Contract Energy Sales Agreements," accessed May 6, 2020. https://www.energy.gov/eere/femp/energy-savings-performance-contract-energy-sales-agreements.
} 
will be able to power $1 / 3$ of the base load. Modular design of the microgrid will allow future expansion and integration of generation assets to power the entire base.

\section{Power Purchase Agreements}

Power purchase agreements (PPAs) ${ }^{11}$ allow federal agencies to implement on-site distributed energy projects with no or minimal up-front capital costs. The developer finances and installs the equipment, and the agency buys the power at a cents/kWh rate based on a competitive procurement. The PPA may or may not include a minimum power purchase provision in the contract. The developer owns the equipment, assumes performance risk, and provides O\&M, repair, and replacement of equipment for the term of the contract. A PPA may not be able to fund a microgrid, but it could be used to finance a component such as a large PV system, which could be incorporated into a microgrid system.

One challenge is that if a PPA was previously used to implement DERs prior to a current microgrid effort, that contractual arrangement may not allow those DERs to be included in the microgrid. The agency will have to obtain permission from the PPA provider/DER owner to include the asset in the microgrid, likely requiring renegotiation of contract terms and pricing if the owner agrees.

Authority to use this mechanism and the contract term allowed varies across the federal government - the longer the allowable contract term, the more flexibility in financing DERs. Civilian agencies must either obtain delegation from General Services Administration (GSA) to use their authority per Federal Acquisition Regulation Part 41 (40 U.S.C. 501) to enter into a PPA, or use GSA or Defense Logistics Agency (DLA) to conduct the procurement. Civilian agency PPAs are limited to a 10-year term. For federal facilities located in their territory, the Western Area Power Administration (WAPA) has authority to enter into a PPA on their behalf for a 20-year term (possibly longer). Department of Defense has a 30-year authority (10 USC 2922a) that can be used for PPAs at DOD sites.

\section{Other Procurement Approaches}

Enhanced use lease (EUL): A few agencies have the authority to use an EUL agreement, which allows underutilized federal real property to be leased for energy development in exchange for in-kind consideration or payment. In this scenario, an agency may be able to enter into an EUL that exchanges a land lease for development of DERs and/or a microgrid. The DERs or microgrid provide power to the commercial grid under normal conditions and provide power to the federal facility in the event of a utility grid outage as in-kind consideration. This can be a cost-effective way to implement a microgrid in cases where all or a portion of implementation, operation, and maintenance costs are covered by the developer, and where the agency would benefit from the resilience provided by the microgrid during a utility grid power outage.

Utility privatization (UP): UP is another approach that may have potential for financing microgrid implementation, if an agency has the appropriate authority to enter into this type of agreement. UP transfers ownership of the entire facility electric distribution system, as well as responsibility for its operation, maintenance, repairs, upgrades, and energy systems performance, to a third-party utility provider. Where a microgrid may be necessary to meet reliability and resilience requirements, the private owner of the system may be able to install the microgrid with the agency repaying the costs through UP payments over the term of the contract.

Energy-as-a-Service (EaaS): EaaS is an emerging business model in the commercial and municipal building sectors but is not currently authorized for use by federal agencies. EaaS allows entities to procure energy services, equipment, and commodities through a single, streamlined agreement. Services could include hardware and software to allow demand response load shedding; implementation, operation, and maintenance of energy efficiency and DER measures; and potentially operation and maintenance of the electrical

\footnotetext{
${ }^{11}$ For more information on PPAs see FEMP, "Federal On-Site Renewable Power Purchase Agreements,” accessed May 6, 2020. https://www.energy.gov/eere/femp/federal-site-renewable-power-purchase-agreements.
} 
distribution system. The Air Force is currently exploring EaaS as a new procurement strategy which may result in an approach that can be used for Department of Defense and possibly other federal agencies (U.S. Air Force 2020).

\section{Implementation Considerations}

Once a funding approach has been chosen, it is recommended (based on agency best practices and lessons learned) to procure the microgrid project as a "design-build" project rather than as "design-bid-build" project if possible (Booth et al. 2019). A design-build process may require special justification in some agencies, but this approach will most likely lead to the best successful project outcome. Due to the complexity and novelty of microgrids, including the depth of integration with existing systems and infrastructure, it is virtually impossible to complete $100 \%$ of the design before proceeding to bid. The primary reason for this is that complete and current as-built documentation of the site utility distribution system can be deficient prior to microgrid implementation. This frequently necessitates design changes during microgrid implementation, as differences are discovered between pre-implementation documentation and actual conditions.

If the procurement must be design-bid-build, it is important to keep the designer of record on the project team throughout the bid and build phases of the project. The designer of record has stamped the design as a Professional Engineer and will need to answer questions and make design changes as construction proceeds. For additional guidance on implementation, see Microgrids for Energy Resilience: A Guide to Conceptual Design and Lessons from Defense Projects (Booth et al. 2019).

\section{A Phased Approach}

If funding constraints do not allow implementation as a single procurement, an agency may need to take a phased approach to microgrid development. If a phased approach is used, it is important to have a well-defined concept by the time the initial phase is awarded. Design and implementation decisions made early in the process will affect how the components of the microgrid can be integrated over time. Special consideration should be paid to proprietary systems, such as the control system, that will need to be updated as the project expands. These decisions will affect how easily the microgrid can be modified or expanded over the long term to support both known and unknown future conditions.

There may be benefits to using a phased approach for microgrid implementation. If a phased approach is taken to procure and install a microgrid to serve one or two buildings at a time, design and implementation lessons can be incorporated into future phases. This can reduce resources needed for implementation. While not impossible to achieve with multiple contractors, these benefits can best be optimized by using the same contractor for all phases of the project.

One approach to time phasing is to install the microgrid over several years as multiple, smaller "microgrid ready" DER projects, with networking, controls, and other components installed once the individual DER components have been implemented. The main risk with this approach is that each component may be designed and installed as a different project on a different timeline, by different contractors, and will thus be optimized at the individual project level rather than as a microgrid system. While it is possible to procure a microgrid in this way, due to the complexity of such a project, the agency may end up with a suboptimal result. In addition, if system performance guarantees are required or desired, contractor guarantees can be compromised if multiple contractors build separate pieces of an integrated system. Even determining which contractor is at fault if there is lack of performance can be difficult or impossible. If implemented as multiple discrete projects, the complete system needs an overarching design for integration, and should be optimized through a commissioning process once all individual projects are installed, so this will need to be included in planning and budgeting.

In addition to technical risk, there is financial and contract risk associated with a phased approach. A financial risk is that funding may be available for early project phases, but adequate funding may not be available for 
later phases. There may also be contract risk related to agreements that were previously put in place to procure DERs as described above under Existing Systems.

One way to mitigate the risk introduced by implementing a microgrid as multiple projects is to consider each project as a stand-alone effort. This can also be thought of as a "modular" approach. Ensure that each project provides value on its own and its value is not dependent on future projects. If future projects do not get funded, the agency would still get value from the current project. It is also important to consider early projects in the microgrid implementation cycle as foundational to the desired microgrid. Future projects should build on what was installed in earlier phases. Ongoing projects that expand the microgrid should avoid, or at least minimize, the need to replace equipment or reconfigure the system or infrastructure installed earlier in the microgrid implementation cycle.

\section{Conclusion}

Finding solutions to enhance energy resilience is a growing concern for many federal agencies. A microgrid is one solution to comprehensively increase access to continuous and reliable electricity for critical loads at a site, whether for a single building or multiple buildings on a campus. This paper highlights several ways to procure and finance microgrid implementation, either through appropriated funding, or by leveraging the savings a microgrid may generate to support third-party financing where federal appropriations are not available.

While third-party financing such as UESC, ESPC (including ESPC ESAs), and USC may provide a considerable share of microgrid financing, the best path forward may be leveraging a combination of avoided costs and appropriated funds to enhance a financed project. These financing mechanisms are very flexible and can be used to provide solutions to all or part of a site's resilience and energy needs; can be implemented at once or phased over multiple years; can be designed to the level of reliability required by the mission; and can focus on only a microgrid, or combine any number of energy efficiency measures into the project.

Federal, state, and utility incentives that apply to microgrid components and strategies can help offset costs. The microgrid may also provide value to the utility electric grid which could result in income streams that improve the payback period. While the ideal approach to implementation would be to design and install the microgrid system as a single project, funding may not allow this, so a phased approach may be more achievable, especially when depending on appropriated funding. The risks of phased implementation should be compared to the benefits when planning an implementation approach.

\section{Getting Started}

Given the technical considerations and a number of procurement options for implementing a microgrid, determining where to start can be a challenge in itself. A general recommended approach is provided here, and the Federal Energy Management Program (FEMP) can provide support in determining a site-specific process.

- First, determine your agency and site-specific energy goals, critical loads, and resilience needs. The Technical Resilience Navigator (TRN) can help the site identify site characteristics such as critical loads and condition of existing infrastructure.

- Discuss goals, needs, and plans with serving utilities early in the process. The utility needs to understand what projects (interconnection of DERs, ability to island, etc.) may affect their system, and may offer programs that support agency energy and resilience efforts. The agency needs to understand utility regulations, rate structures, and offerings that may impact microgrid implementation.

- If appropriations are not available, pursue using a UESC or ESPC to use private-sector funds to finance the microgrid. UESCs and ESPCs include O\&M, repair and replacement, and M\&V as added benefits to the agency. Consider leveraging energy and water efficiency upgrades and the potential for avoided costs to improve resilience and payback. 
- If private ownership of DERs are desired for technical or financial reasons, consider implementing DERs as ESA ECMs under an ESPC; consider a comprehensive approach with other ECMs for maximum benefit.

- If a phased approach must be taken, ensure the concept is well-defined before the first contract is awarded. Decisions made early in the process will affect the effectiveness of the microgrid system. In addition to technical details, consider how ownership models may affect the outcome. Also consider future expansion, and the ease with which new DERs and loads can be added.

The U.S. Department of Energy Federal Energy Management Program (FEMP) has a wealth of expertise and resources to help an agency determine the best approach for a specific project. FEMP can also help in the implementation of a microgrid project with special expertise and resources for ESPCs and UESCs. 


\section{References}

Booth, Samuel, James Reilly, Robert Butt, Mick Wasco, and Randy Monohan. 2019. Microgrids for Energy Resilience: A Guide to Conceptual Design and Lessons from Defense Projects. NREL/TP-7A40-72586. Golden, CO: National Renewable Energy Laboratory. https://www.nrel.gov/docs/fy19ost.

Electric Power Research Institute. 2016. Microgrids: Expanding Applications, Implementations, and Business Structure. https://www.epri.com/\#/pages/product/3002008205/.

Federal Energy Management Program (FEMP). 2009. Practical Guide to Savings and Payments in FEMP ESPC Task Orders Rev 3. https://www.energy.gov/sites/prod/files/2013/10/f3/practguide_sav_paymnts.pdf.

EERE. 2020a. "Food and Drug Administration White Oak Campus Environmental Stewardship and Cost Savings." https://www.energy.gov/eere/femp/downloads/food-and-drug-administration-white-oakcampus-environmental-stewardship-and-cost.

EERE. 2020b. "Navy Rachets Up Resilience Through Agency/Utility Collaboration". DOE/GO-102020-5235. https://www.energy.gov/eere/femp/downloads/navy-ratchets-resilience-through-agencyutilitycollaboration.

FEMP. 2019a. "Investment Tax Credit Requirements for Privately Owned Solar Photovoltaic Systems on Federal Sites." DOE/GO-102019-5197. https://www.energy.gov/eere/femp/downloads/investment-tax-creditrequirements-privately-owned-solar-photovoltaic-systems.

FEMP. 2019b. “An Integrated Approach to Resilience.” DOE/EE - 1905.

https://www.energy.gov/sites/prod/files/2019/05/f62/femp-resilience_0.pdf.

FEMP. 2020a. "FEMP Technical Resilience Navigator.” Accessed May 6, 2020.

https://femp.energy.gov/resilience/.

FEMP. 2020b. "Energy Savings Performance Contracts for Federal Agencies.” Accessed May 6, 2020. https://www.energy.gov/eere/femp/energy-savings-performance-contracts-federal-agencies.

FEMP. 2020c. "Utility Energy Service Contracts for Federal Agencies,” Accessed May 6, 2020. https:/www.energy.gov/eere/femp/utility-energy-service-contracts-federal-agencies.

FEMP. 2020d. "Federal On-Site Renewable Power Purchase Agreements," Accessed May 6, 2020. https://www.energy.gov/eere/femp/federal-site-renewable-power-purchase-agreements.

FEMP. 2020e. "Energy Savings Performance Contract Energy Sales Agreements," Accessed May 6, 2020. https://www.energy.gov/eere/femp/energy-savings-performance-contract-energy-sales-agreements.

IEEE. 2012. 1366-2012 - IEEE Guide for Electric Power Distribution Reliability Indices. https://standards.ieee.org/standard/1366-2012.html.

International Organization for Standardization. 2018. Reciprocating internal combustion engine driven alternating current generating sets - Part 1: Application, ratings and performance ISO 8528-1:2018. https://www.iso.org/standard/68539.html.

National Renewable Energy Laboratory. 2018. "Federal Tax Incentives for Energy Storage Systems." NREL/FS-7A40-70384. Golden, CO: National Renewable Energy Laboratory. https://www.nrel.gov/docs/fy18osti/70384.pdf. 
N.C. Clean Energy Technology Center. 2020a. "Database of State Incentives for Renewables \& Efficiency." Accessed May 6, 2020. https://www.dsireusa.org/.

N.C. Clean Energy Technology Center. 2020b. "Business Energy Investment Tax Credit (ITC).” Accessed May 6, 2020. https://programs.dsireusa.org/system/program/detail/658.

U.S. Energy Information Administration. 2019. Annual Electric Power Industry Report, Form EIA-861 Detailed Data Files. https://www.eia.gov/electricity/data/eia861/.

U.S. Air Force. 2020. “Energy-as-a-Service.”

https:/www.safie.hq.af.mil/Portals/78/documents/IEE/Energy/EaaS_2020fact\%20sheet_final.pdf?ver=202006-19-141911-837. 
(This page intentionally left blank) 
ENERGY EFFICIENCY \& RENEWABLE ENERGY 